\title{
Knowledge and Perception of Dental Fluorosis in the Populations of Ferlo (Senegal)
}

\author{
Massamba Diouf $^{1}{ }^{*}$, Amadou Dieng $^{2}$, Gilles Boetsch $^{1}$, Fadoua OUICH $^{3}$, EngueranMaccia $^{1}$ \\ ${ }^{1}$ Unit Mixte International UCAD-CNRST-CNRS-USTTB-UGB UGB Environment, Health, Society. 45391 \\ Dakar, Fann, Senegal \\ ${ }^{2}$ Public health department/Faculty of Medicine / Cheikh Anta Diop University, Dakar, Senegal \\ ${ }^{3}$ Dentist, practitioner in Dakar, Sénégal
}

*Corresponding Author: Massamba Diouf, Unit Mixte International UCAD-CNRST- CNRS-USTTB-

UGB UGB Environment, Health, Society.45391 Dakar, Fann, Senegal, Email: dioufmass78@yahoo.fr

\begin{abstract}
Objective: The objective of this study was to assess the knowledge of the populations regarding the causes of dental fluorosis and to understand the perception it generates.
\end{abstract}

Methods: The study was descriptive and qualitative in individuals with dental fluorosis. The information were collected by an interview guide concerned the knowledge about dental fluorosis and the perception of fluorosis of the population.

Results: The study population was 60 individuals with an average age of $36.34 \pm 16.06$ years and an $h / f$ ratio of 1.03. Dental fluorosis in Widou populations in the Ferlo were variously described with varying definitions and aetiologies. The populations also had a negative perception of people suffering from fluorosis with psycho-social consequences.

Conclusion: This study had made a number of findings regarding the perceptions of dental fluorosis in the Widou in Ferlo population. These results also recommend the implementation of new strategies to be integrated into policies in order to improve oral health status.

Keywords: Knowledge, Perception, Fluorosis, Ferlo, Senegal

\section{INTRODUCTION}

The protective action of fluoride against dental caries has been known for about 50 years and has since become one of the essential elements in oral prevention. Fluorides are omnipresent in drinking water, toothpastes, table salt, milk, food or fluoride supplements [1]. Minimum and maximum desirable levels of fluoride in public water supplies have been defined by the World Health Organization (concentrations between 0.9 and $1.2 \mathrm{mg} \mathrm{/1)} \mathrm{[2].} \mathrm{However,} \mathrm{in} \mathrm{some} \mathrm{parts}$ of the world, due to soil, water supply tests have indicated naturally occurring fluorides that cause health problems [3]. However, their ingestion in excessive doses poses the problem of their long-term toxicity. Indeed, under these conditions, fluorides can be responsible for many chronic dental and skeletal diseases, also called "fluorosis". This type of intoxication, contrary to acute intoxication, is most often encountered in people exposed via their profession, populations living near factories or populations residing for many years in a region where fluorides are naturally present in excessive quantities in drinking water [14]. Dental fluorosis can sometimes represent a major aesthetic damage by its impact on the color and surface appearance of dental enamel. It gives rise to generations stigmatized by deformations of the tooth surface, a negative impact on the quality of life and health of these people $[5,6]$. In an image-centered society, notions of appearance and aesthetics are more important than ever.

However, despite numerous studies carried out in Senegal that have investigated certain variables (age, gender, activity, migratory movements, source of water supply, contact 
time) and determined the prevalence of bone and dental fluorosis, there is little interest in interpreting the causes and consequences in Ferlo populations [4,7-10] .

In Ferlo, a locality mostly inhabited by Peulhs, the population is strongly attached to aesthetics, especially among women, where white teeth are an important social representation in terms of charm, self-esteem and positive perception of others [11].

With regard to the color caused by the excess of fluoride on the teeth, one could be justified to think that such a situation would lead to attitudes and perceptions on the lived and social environment of the populations. Thus, the objective of this study was to evaluate the knowledge of the populations regarding the causes of dental fluorosis and to understand the perception it generates.

\section{Materials \& Methods}

Type and scope of study

The survey took place in WidouThiengoli in the Ferlo region of central eastern Senegal. It is an area composed essentially of Fulani populations with livestock and trade as their main activities.

\subsection{Selection Criteria and Sampling}

Individuals selected for the semi-structured interview were recruited through accidental sampling and had to be at least 18 years of age to sign the consent form. They also had to be a resident of the area during their first six years of life, have dental fluorosis and have their incisors in their mouth without mutilation.

The sample size was stopped at 60 people when the saturation level was reached. That is to say that from this size on, the information collected would be repeated in other people.

\subsection{Collection Procedure and Variables}

The information collected concerned the knowledge about dental fluorosis (definition, causes, period of appearance) and the perception of fluorosis. The collection of these data was carried out by a dentist assisted by a socioanthropologist, both assisted by an interpreter speaking French and the local language. Prior to the survey itself, discussions were organized to ensure uniformity and fidelity in the translation of the questions asked. This collection took place over a period of ten days from July 22 to 29,2018 . During this collection, in addition to the papers, pens and pencils used to record the questions and answers, a digital camera was used to film the sessions, photograph certain practices and record the speeches among others.

\subsection{Data Analysis}

The data from this survey was processed using the manual method of selecting, condensing, categorizing, and organizing the information using linguistic or numeric codes. Verbatims or boxes and notes were used to compile the results. Qualitative data processing software was also used and the results were expressed in point clouds.

\subsection{Ethical Considerations}

Individuals were given a session to explain the purpose and objectives of the study in order to obtain their free and informed consent. A motivation and hygiene education and/or scaling session was provided if necessary.

\section{Results \& DisCUSSION}

\subsection{Results}

\subsubsection{Description of the Population}

The study population was 60 individuals. The average age of the sample was $36.34 \pm 16.06$ years. It ranged from 18 to 75 years of age. Males were the most represented in the sample with $50.82 \%$, for an $\mathrm{m} / \mathrm{f}$ ratio of 1.03 . The average age of the sample was $36.34 \pm 16.06$ years, ranging from 18 to 75 years.

\subsubsection{General Knowledge about Dental Fluorosis and its Causes}

Dental fluorosis, considered as a dyschromia of the tooth, was known to the Ferlo populations. It was defined as "gnihébonehégnari" in the local language meaning bad teeth. Some participants insisted on the term "gnihékodomhé" in Peulh or red tooth to describe the anomaly. Also in these populations, dental fluorosis was stigmatized. Indeed, individuals with fluoridated teeth were considered negligent for some while others thought "they are lazy because they do not watch over the quality of the water they drink".

Some causes that justify it were evoked. The majority of interview participants cited borehole water, tobacco, and poor hygiene as the main causes. For A.S. "the cattle that drink around the borehole pollute their water and could explain dental fluorosis". The "chocolate" was well underlined among the causes.

As regards the appearance of fluorosis on permanent teeth and not on milk teeth, it was not perfectly known by the populations. Many 
ideas or considerations were highlighted to explain this phenomenon. A woman in her forties justified it by the fact that "the child is protected by God and when he is able to lead the cattle, he becomes strong so he can face the appearance of fluorosis on his teeth. That's why it appears from that moment on".

This cloud of words (fig. 1) illustrates the general knowledge about fluorosis and its causes declared by the populations.

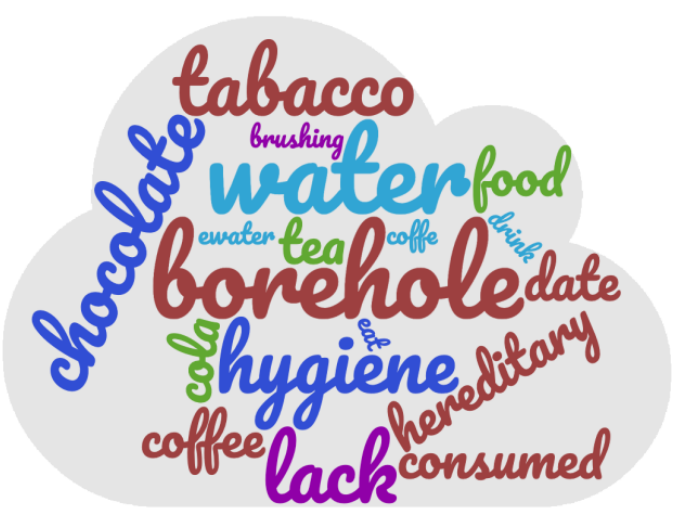

Figure1: Word cloud on the causes of dental fluorosis in Ferlo populations

\subsubsection{The Perception of Dental Fluorosis in Ferlo Populations}

This study allowed us to understand the perception of dental fluorosis in Ferlo populations. These populations felt that other people with dental fluorosis did not look good. Indeed, they thought that dental fluorosis "affects the aesthetic appearance and personality of the individual". F.M 45 years old, said that she is "worried about the appearance of her teeth and sometimes avoid smiling freely or cover her mouth with her hands when smiling".

Among the few respondents who understood that the origin of fluorosis was due to a high fluoride content in the water from the borehole, felt that "the government should play a central role by actively taking measures to prevent dental fluorosis by installing a defluoridation plant". However, some people were more radical and their understanding was that to find a solution to fluorosis it was necessary to "put bleach on their teeth to whiten or even mutilate them".

Despite the significant impact of dental fluorosis on the participants and the awareness of the availability of defluoridation procedures, none of them consulted the dentist about the appearance of their teeth.

\subsection{Discussion}

This study, which took place in the Ferlo, made it possible to analyze the content of fluorine in the waters of beverages consumed, to describe the socio-demographic profile of the populations and to understand the knowledge and perceptions of dental fluorosis of the populations of WidouThiengoli.

\subsubsection{Limitations and Methodological Considerations}

The study was based on semi-structured interviews that were conducted at Widou. A total of 60 individuals were interviewed. The results would, therefore, be difficult to transpose to the rest of Senegal where there may be other types of populations other than the Peulh.

For data collection, an investigator was chosen to make the measurements uniform, without distinctions, in order to limit information bias and to have the same understanding. Ideally, an interpreter living in the locality would have been chosen for the translation of some terms into the local language, but the availability of an interviewer who spoke the language helped to limit these biases.

\subsubsection{Socio-Demographic Characteristics}

The population in our study was relatively young with an average age of 36.34 with \pm 16.06 . This youthfulness of the population is a specific indicator, observed at the national level. This result corroborates the latest Demographic and Health Survey of 2017, which reveals a young population in almost all localities in Senegal [12].

In this sample, there were almost the same number of men as women. However, the results of this study are different from those found by Latyr [9] (56.4\% female and $43.6 \%$ male) in the same population. The size of his sample could highlight the nomadism of men compared to women. However, our results are comparable to those found in national statistics with $50.8 \%$ of women and $49.2 \%$ of men [12].

\subsubsection{General Knowledge on Dental Fluorosis and its Causes}

Dental fluorosis was well known to the Widou populations in Ferlo. They defined it as "gnihébonehégnari" or bad teeth. Some 
participants insisted on the term "gnihékodomhé" in Peulh or red tooth to describe the anomaly. In general, people in the affected areas are relatively familiar with dental fluorosis [13]. For this community, dental fluorosis would be a disease "of the area". This would constitute or create a kind of solidarity conscious of the impact of dental fluorosis on oneself and the looks of others or reaction from outside. For the less affected or unaffected, the knowledge or mastery of dental fluorosis was very limited. They thought that people suffering from fluorosis are like "lazy people who don't take care of the quality of the water they drink". For others, "it's the disease of careless people"they said most often. These interpretations could be explained by the similarities to poor oral hygiene.

Causes attributed to dental fluorosis have been evoked by Widou populations. The majority of participants in the interviews cited borehole water, tobacco, and poor hygiene as the main causes. Dental fluorosis results from excessive ingestion of fluoride during the formation of the dental organ and more specifically during amelogenesis. It is generally promoted by the significant accumulation of fluoride ions not only from water but also from sources of fluoride supply (food, air ...). Indeed, there are several of them, all of which are likely to cause dental fluorosis [14]. However, milk and tea, two products very consumed in the Ferlo due to the dietary habits of the population, are rich in fluoride. It is therefore likely that, in addition to the well water that originates from the Maestrichian water table, the consumption of these two products could contribute to the occurrence of fluorosis.

As regards the appearance of fluorosis on permanent teeth and not on milk teeth, it was not perfectly known by the populations. This dental fluorosis inevitably affects groups of teeth that are usually the incisors but also the other permanent teeth, namely the premolar and molar canines. In fact, each of them develops at different times, hence the observation of symmetrical attacks that coincide between the time of fluoride intake and the period of enamel mineralization. These two parameters are closely related and determine the prevalence and severity of fluorosis. Since teeth are much more sensitive at the very beginning of amelioration, (risk period), they can undergo structural changes that weaken their resistance.
In fact, the first two years of life are considered the period of maximum susceptibility to fluorosis and more specifically for teeth that erupted early. Specifically, it has been shown that the period of greatest susceptibility to fluorosis in the permanent maxillary central incisors is around 15-24 months in men and 2130 months in women [15]. Temporary incisors, on the other hand, begin their amelogenesis period at the 14th week intrauterine and end at about 11 months [16]. 16] This makes the possibility of dental fluorosis in milk teeth rare, as a woman in her forties explained differently by the fact that "the child is protected by God and when he is able to lead cattle, he becomes strong so he can cope with the appearance of fluorosis on his teeth. That's why it appears from that moment on".

\subsubsection{The Perception of Dental Fluorosis in Ferlo Populations}

Perceived health status is an important and essential measure in assessing the health of a population. This measure, usually based on a single question, simply reflects people's overall appreciation of their own health. In populationbased surveys, interviewers tend to remind participants that health is not only the absence of disease or infirmity, but also a state of physical, mental, and social well-being [17].

In this sense, Widou populations were led to perceive their health status in relation to dental fluorosis. The result was that people with dental fluorosis did not have a good appearance. This is the finding noted in the study by Chankanka O Levy et al [18], which focused on the psychosocial impact, aesthetics, tolerance and self-acceptance in people with dental fluorosis in Malaysia. Their work indicated that the nonaesthetic perception and psychosocial impact of dental fluorosis was noticeable in participants with dental fluorosis. Approximately $18 \%$ of the 104 subjects in the study covered their mouths with their hands to laugh or smile, $8.7 \%$ avoided going out or hanging out with friends. Furthermore, Riordan's work [19] showed that the aesthetic challenges caused by dental fluorosis is more of a problem for girls than for boys. The perception of the disease or its description still remains at the level of tooth coloration. Through a plate [20] of dental fluorosis shown to the respondents, to indicate their preference for tooth color and to indicate sick and healthy teeth, the respondents had opted for white. According to them, white means healthy and clean teeth. The authors 
wanted to demonstrate that aesthetics is related to the whiteness of the tooth. Non-white teeth are unaesthetic and diseased teeth. Therefore, even apparently white teeth can also be fluoridated. The yellowish or reddish coloration of the fluoridated tooth is related to the concentration of fluoride in the teeth. Dental fluorosis has also been shown to affect the quality of life of those affected. In addition to subjective factors related to self-perception, environmental factors should be taken into account to assess the impact of dental fluorosis on the quality of life.

Individuals who understood the origin of dental fluorosis (fluoride poisoning) felt that it was up to the governor to find the solution that exceeded their limits. It is generally accepted that ingestion of excess fluoride, most often in drinking water, can cause dental fluorosis that damages teeth and bones. Paradoxically also, consuming fluoride in low doses helps prevent tooth decay. Controlling the quality of drinking water is therefore essential to prevent dental fluorosis.

The fight against this scourge in Widou would start on the one hand by defining its main causes, namely the fluoridation of water from the mæstrichtian aquifers (drilling), but also diet and excessive consumption of tea, and on the other hand by advocating for the defluoridation of water. Treatment of water to remove excess fluoride should be considered. It presupposes that socio-economic factors are taken into account beforehand.

Despite the significant impact of dental fluorosis on the participants and the awareness of the availability of defluoridation procedures, the Widou populations suffering from fluorosis had never consulted a dentist about the appearance of their teeth. Overall, it was noted that more than $80 \%$ of the African population south of the Sahara use traditional medicine as a first-line treatment [22]. As evidenced by the work of Diouf et al [23] on Widou populations. Numerous studies have placed the intervention of traditional practitioners at three levels: prevention and protection against misfortune, detection of the causes of imbalances observed in patients, and eventual problem solving [2426]. Traditional oral health care would follow the same logic. The fact that a dentist is not used for the diagnosis of fluorosis and the proposal of cosmetic treatment would be linked to their complexity in the popular African imagination. In fact, oral diseases have a bad reputation because the mouth would be par excellence, the target organ of spell casters. The treatment of oral diseases is reserved for initiates and certain castes [27].

\section{CONClusion}

This study had made a number of findings regarding perceptions of dental fluorosis in the population of Widou au Ferlo.

These results also recommend the implementation of new strategies to be integrated into policies in order to improve oral health status by implementing preventive and curative approaches based on awareness and communication for the development, accessibility and availability of oral health services.

\section{ACKNOWLEDGEMENTS}

This article acknowledges with satisfaction the work of the UMI3189 researchers who designed and implemented the original study and the populations of the Ferlo

\section{REFERENCES}

[1] ROZEL D. Fluorosis of the anterior teeth. Thesis: Chir Dent: Lyon N ${ }^{\circ}$ 2012LYO1D000. (2012).

[2] WORLD HEALTH ORGANIZATION (WHO). The problem of fluoride in drinking water, Geneva. (2006)

[3] WORLD HEALTH ORGANIZATION (WHO). Dental and bone fluorosis after prolonged excessive exposure. (2011).

[4] CARITAS SENEGAL. Epidemiological survey: impact of fluorine ingested via drinking water on the health of populations of $5 \mathrm{CRs}$ in Senegal: 43p.(2009)

[5] CASTILHO LS, FERREIRA EF, VELASQUEZ LN, FANTINEL LM, PERINI E. Beliefs and attitudes regarding endemic dental fluorosis in adolescents in rural areas of Brazil. Revista de SaudePublica 44 (2): 261-266.(2010)

[6] CASTILHO LS, FERREIRA EF, PERINI E. Perceptions of adolescents and young people regarding endemic dental fluorosis in a rural area of Brazil: psychosocial suffering. Health \& Social Care in the Community. 17 (6): 557-63.(2009)

[7] YANG Y, WANG X, GUO X. Effects of high iodine and high fluoride on children's intelligence and iodine and fluoride metabolism. Zhonghua Liu Xing Bing XueZaZhi. 15 (5): 296-8.(1994)

[8] BROWNE D, WHELTON H, O'MULLANE D. Fluoride Metabolism and Fluorosis. Journal of Dentistry.33 (3): 177-86. (2005) 
[9] PAPA LATYR DIOUF. Prevalence and factors associated with dental fluorosis in Ferlo (Senegal). Thesis: chir.dent. Dakar, UCAD $n^{\circ}$ 44. (2018)

[10] ARBAB CHIRANI R, FORAY H. Dental fluorosis: etiological diagnosis. Pediatric Archives. 12 (3): 284-7. (2005)

[11] DIOUF M, BOETSCH G, CISSE D., TAL-DIA A, JJ BONFIL. Lifestyles and oral health in the Fulani populations of Ferlo in Senegal.Médecine et Santé Tropicales. 22 (2): 187-92. (2012)

[12] AGENCE NATIONALE DE LA STATISTIQUE ET DE LA DEMOGRAPHIE Population of Senegalin2017.MEFP.ANSD (2017) http://www.ansd.sn/ressources/publica tions/Rapport_population_2017_05042018.pdf Consulted on 09/12/2019

[13] ANDREAS SCHULD Effect of fluorine on the activity of the enamel matrix. European Journal of Oral Sciences. 108 (1): 48-53. (1999)

[14] DENBESTEN PK, LI W. Chronic fluoride toxicity: dental fluorosis. Monographs in oral science. (22): 81-96. (2011)

[15] GUO J, LYARUU DM, TAKANO Y et al. Amelogenins as potential buffers during amelogenesis at the secretion stage. Dental Research Journal. 94: 412-420. (2015)

[16] KILPATRICK N. "New Developments in Understanding Enamel Developmental Defects: Optimizing Clinical Outcomes". J. Orthod. 36 (4): 277,282. (2009)

[17] WORLD HEALTH ORGANIZATION (WHO). Preamble to the Constitution of the World Health Organization, as adopted by the International Conference on Health, New York, June 19-July 22, 1946(1946)

[18] CHANKANKA O LEVY SM, WARREN JJ, CHALMESS J M. A review of the literature on aesthetic perceptions of dental fluorosis and the relationship with psychosocial aspects / oral health - quality of life related to oral epidemiology -community dental .38 (2): 97109. (2010)
[19] Riordan PJ. Perceptions de la fluorose dentaire. Journal de recherche dentaire. 72 (9): 1268-1274. (1993)

[20] MCGRADY MG 1, ELLWOOD RP, GOODWIN M, BOOTHMAN N, PRETTY IA, Adolescent Perceptions of the Aesthetic Impact of Dental Fluorosis VS. Other dental conditions in areas with and without water fluoridation, License BIOMED CENTRAL Ltd. 12 (1): 4. (2012;)

[21] SUZELY ADAS SALIBA MOIMAZ. Dental fluorosis and its influence on children's lives, UNESP. 29:14. (2014)

[22] WORLD HEALTH ORGANIZATION REGIONAL OFFICE FOR AFRICA. Promoting the Role of Traditional Medicine in Health Systems: A Strategy for the African Region 2001-2010. World Health Organization AFR / RC50 /. 2000. (2011)

[23] DIOUF M, BOETSCH G, KA K, TAL-DIA A, JJ BONFIL. Socio-cultural aspects of oral health among the Fulani of Ferlo (Senegal): a qualitative study.ActaOdontol Scand. 71 (5): 1290-5. (2013)

[24] MC CALLUM TG. White women witchdoctor - Tales of African life by Rae Graham. Ed. Fielden delivers Fla. Miami, (1992).

[25] NGUBANE H. Clinical practice and organization of indigenous healers in South Africa. SocSci Med B. 15 (3): 361-365. (1981)

[26] RANTALA E, KODZWA GM, VIISAINEN K, DIODIO R, OSAKI S, FRELING D. Baseline study Health care: Manica province integrated health project v1. Internal report of the Ministry of Health. Republic of Mozambique (1992).

[27] TOURE S, KATTIE A-L, DJEREDOU B, BAKAYOKO - LY R.Symbolism of the oral cavity. Rev. Collar. Odonto-Stomatol. Chir. Maxillo-Fac. Afr. 4: 19-24. (1997)

Citation: Massamba Diouf, et.al, Knowledge and Perception of Dental Fluorosis in the Populations of Ferlo (Senegal).ARC Journal of Public Health and Community Medicine. 2020; 5(4):18-23. Doi:doi.org/10.20431/24 56-0596.0504003.

Copyright: (C) 2020 Authors. This is an open-access article distributed under the terms of the Creative Commons Attribution License, which permits unrestricted use, distribution, and reproduction in any medium, provided the original author and source are credited. 